\title{
Effect of agro-forestry and landscape changes on common buzzards (Buteo buteo) in the Alps: implications for conservation
}

\author{
Fabrizio Sergio ${ }^{1,2, *}$, Chiara Scandolara ${ }^{2}$, Luigi Marchesi ${ }^{2}$, Paolo Pedrini ${ }^{2}$ and Vincenzo Penteriani ${ }^{3}$ \\ ${ }^{1}$ Edward Grey Institute of Field Ornithology, Department of Zoology, South Parks Road, Oxford, UK \\ 2 Raptor Conservation Research Unit, Trento Natural History Museum, via Calepina 14, 38100 Trento, Italy \\ ${ }^{3}$ Department of Applied Biology, Estación Biológica de Doñana, C.S.I.C., Avda. de María Luisa s/n., Pabellón del Perú, Apdo 1056, 41013 Seville, Spain \\ (Received 4 December 2003; accepted 20 May 2004)
}

\begin{abstract}
In Italy, pre-Alpine forests, once managed through coppice silviculture, are being converted to mature woodland, while land abandonment is causing woodland expansion and erosion of open habitats. Based on habitat-selection analyses, we predicted the impact of such changes on common buzzards (Buteo buteo), which depend on forested and open areas for nesting and foraging. Compared to availability, at a micro-scale buzzards selected nests higher above ground and on trees frequently covered by ivy. At the landscape-scale, buzzards avoided roads and conspecifics, while selecting rugged areas with high habitat heterogeneity, probably related to a varied food supply. Productivity was related to the availability of arid habitats, probably because of their richness in main prey species. Finally, population density was negatively related to the abundance of eagle owls (Bubo bubo), a potential predator of adults and nestlings, and positively related to the availability of woodland, a low predation-risk habitat rich in food and nest-sites. Therefore, buzzard settlement, density and productivity depended on the complex interplay of food availability, human persecution and predation risk. Thus, the current landscape changes would benefit buzzards by providing more nest-sites, but would be detrimental because of the lower productivity associated with the disappearance of dry open areas. Proposed conservation guidelines focus on conversion of coppice woodland to mature forests and active management of dry heath, a conservation sensitive habitat, through controlled burning.
\end{abstract}

\section{INTRODUCTION}

The traditional landscape of the European Alps is going through a relatively fast process of land-use changes. In the lower-elevation mountains of the pre-Alps, the landscape was traditionally dominated by large forests interspersed with open habitats, mainly meadows. The forests were managed using a coppice silvicultural system (Matthews, 1989), while open habitats were artificially maintained for livestock grazing and hay production, an agro-forestry and pastoral system that dates back to 6000 years ago (Lichtenbergen, 1994). The management practices of both these landscape features have rapidly changed in the past decades because of land abandonment associated with the declining profitability of livestock rearing and coppice silviculture (Buckley, 1992; CIPRA, 2001). As a result, open habitats are being rapidly lost through shrub encroachment and woodland expansion (e.g. Pedrini \& Sergio, 2001, 2002), while large areas of forest have

${ }^{*}$ All correspondence to: Fabrizio Sergio. Raptor Conservation Research Unit, Museo Tridentino di Scienze Naturali, Via Calepina 14, 38100 Trento, Italy. E-mail: fabrizio.sergio8@tin.it been left unmanaged for 3-4 times the original rotation of 10-20 years (Sergio, Pedrini \& Marchesi, 2003d). Some of these forests are naturally evolving into mature forest, while incentives from local administrations and the Common Agricultural Policy (C.A.P.) of the European Union favour their conversion to mature woodland (e.g. I.P.L.A., 2000). Therefore, large areas of forest are planned or likely to be converted to mature timber. Such radical changes impose an urgent need for investigation of their potential impact on the local fauna and for conservation proposals based on quantitative studies. This would increase the probability of integrating them into forestry plans and incentive schemes (e.g. C.A.P. subsidies, or timber certification: Pain \& Pienkowski, 1997; Bennet, 2000).

Here, we provide such a study by focusing on the common buzzard (Buteo buteo), a medium-sized diurnal raptor widely distributed throughout the Palearctic. In the Italian Alps, its populations are stable, although few quantitative data are available (Sergio et al., 2002) and nothing is known of its habitat requirements. Nests are uniformly dispersed and located on cliffs or trees (Sergio et al., 2002). The diet is dominated by snakes, mainly 
occurring in open, arid habitats and by various woodland species of small mammals and birds (Scandolara \& Sergio, 2001).

Here, we (1) analyse the factors affecting nest-site selection by buzzards, (2) examine the reproductive consequences of such habitat choices, (3) investigate the population effects of spatial variations in habitat quality, (4) predict the potential impact of the ongoing landuse changes and (5) propose conservation-management

guidelines. We assume that, if the above-cited landscape changes negatively affect the populations of such a generalist species, they could affect even more the populations of other more exigent and specialised species.

\section{STUDY AREAS}

The study area was a $130-\mathrm{km}^{2}$ plot located in the central Italian pre-Alps $\left(45^{\circ} 55^{t} \mathrm{~N}, 8^{\circ} 50^{t} \mathrm{E}\right)$, near the shore of Lake Lugano (hereafter 'Lugano area'). Elevation ranged from 275-1125 m above sea level (a.s.l.). The landscape was characterised by mountain slopes covered by deciduous woodland, interspersed with small to medium-sized cliffs and scarce open areas, caused by regular burning or sheep grazing and mainly covered by grassland and sparse bushes. The valley floors were intensively cultivated or urbanised.

Woodland was mainly dominated by deciduous species, originally managed as coppice but now left unmanaged (neglected coppice: Buckley, 1992). As a result, most of the woodland consisted of a homogeneous cover of young second-growth forest. Mature trees, originally retained as seed bearers, were scarce and present as widely scattered individuals or in small clumps (coppice with standards system: Matthews, 1989). In particular, $21 \%$ of the woodland area was dominated by sweet chestnut (Castanea sativa), $20 \%$ by European beech (Fagus sylvatica), $19 \%$ by a mixture of sweet chestnut and oak species, $18 \%$ by European hop-hornbeam (Ostrya carpinifolia), $5 \%$ by oak species, $5 \%$ by locust (Robinia pseudoacacia), $2 \%$ by conifers and $10 \%$ by other tree species (Geographic Information System (GIS) analysis from Tosi et al., 2000).

To further test the effect of environmental variables on buzzards at the population-level, between 1996 and 2000 we censused buzzards in eight other study areas scattered throughout the Italian Alps (Fig. 1). The landscape and elevation of all of these areas was comparable to that of the Lugano plot (for details, see Sergio, Marchesi \& Pedrini, 2003a; Sergio, Pedrini \& Marchesis, 2003b). A further $100-\mathrm{km}^{2}$ study plot, located along the Noce Valley, was surveyed in 2001-2002.

\section{METHODS}

\section{Field surveys and nest checks}

In the Lugano area, buzzards were monitored between 1993 and 2003. We censused territorial pairs by looking at territorial displays and transfers of nest material during

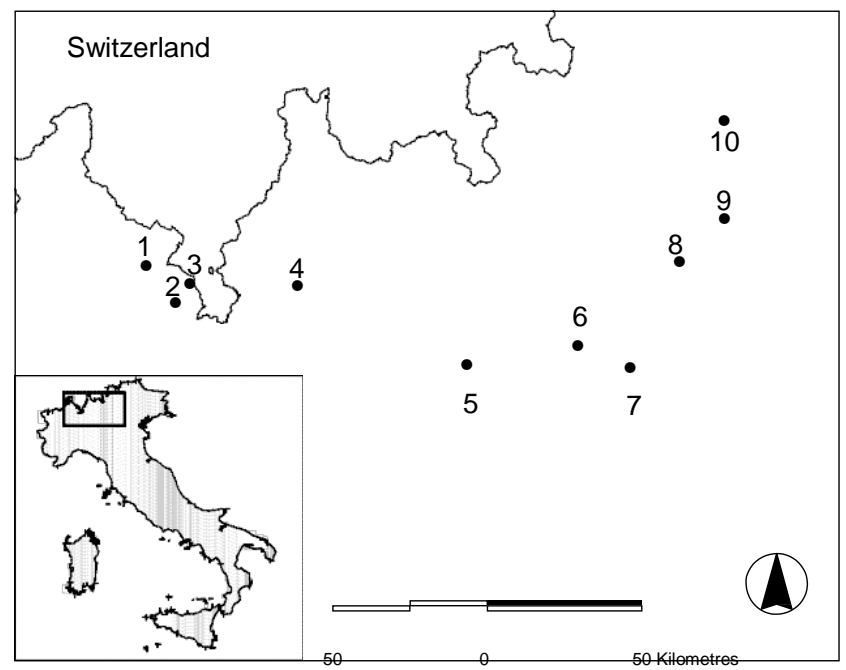

Fig. 1. Location of common buzzard study areas in the Italian Alps (1993-2003): 1, lake Maggiore study area; 2, Lugano; 3, Ganna Valley; 4, Lecco; 5, Lake Iseo; 6, Idro; 7, Lake Garda; 8, Sarca Valley; 9, Adige Valley; 10, Noce Valley.

the pre-incubation period. Nests were visited when the nestlings were older than 45 days to record the number of fledged young (Sergio et al., 2002). Because of manpower limitations we collected only data on density in the other areas. Furthermore, we censused nests of eagle owls (Bubo $b u b o$ ) in all the areas, because this species frequently prey on other raptors and may limit their populations (Marchesi, Sergio \& Pedrini, 2002; Sergio et al., 2003a). Eagle owls were absent from the Lugano area.

\section{Selection of nesting habitat}

The Lugano area supported a stable population of 40 buzzard territories. To avoid pseudo-replication, in each analysis we used only one randomly selected nest among the alternative ones of each territory. Since nesting habitat selection may occur at multiple spatial scales (e.g. Sergio \& Bogliani, 2000; Penteriani, Faivre \& Frochot, $2001 a$ ), we carried out analyses (1) at a micro-scale, at the level of the nest-site and its immediate surroundings and (2) at a landscape or macro-scale, within a circle of 700-m radius centred on the nest. The measure of $700 \mathrm{~m}$ was chosen because this is approximately half the mean nearest neighbour distance (NND) in our population (Sergio et al., 2002). Since buzzards nest both in trees and on cliffs in our area, analyses at the micro-level were carried out separately for the two nest types.

To analyse factors affecting selection of cliff nests, we compared the variables recorded at 25 independent cliff nests (i.e. each from a different territory) with those recorded at 25 random cliffs (Appendix 1). To analyse factors affecting the selection of tree nests, we compared the variables recorded at 25 independent tree nests with those recorded at 25 random trees (Appendix 1). All random locations (cited above and below) were generated by means of the extension 'Animal Movement' in the GIS software ArcView (Hooge \& Eichenlaub, 1997). 
For tree nests, random trees were selected by (1) reaching the random location, (2) walking $100 \mathrm{~m}$ from it towards the North to minimise inadvertent observer bias (Redpath et al., 1998) and (3) selecting the nearest tree judged capable to support a hypothetical buzzard nest at $>8 \mathrm{~m}$ high (i.e. $1 \mathrm{~m}+$ the minimum height above ground of buzzard nests recorded in this study). To assess whether buzzards selected specific woodland features in the immediate surroundings of the nest, we measured variables related to woodland composition and structure within a 0.04-ha circular plot centred on each tree (see Appendix 1).

To analyse factors affecting selection of nest-sites at the landscape level, we compared the variables collected within $700 \mathrm{~m}$ of 40 independent nests and of 40 random locations (Appendix 1). Percentage extent of land-use types in the circle were calculated by accessing 1:10 000 land-use maps (Tosi et al., 2000). Since 26 out of the 40 randomly chosen nests were positioned on cliffs and 14 on trees, we plotted 26 random locations on cliffs and 14 on trees. Furthermore, the minimum NND between random locations was set to be the same as the minimum NND between buzzard territories. Overall, measured variables (Appendix 1) were related to (1) the structural characteristics of the nest-site and its immediate surroundings, (2) the distance to conspecifics, potential hunting grounds or sources of human disturbance and (3) the structure and composition of the landscape (see Austin et al., 1996 for a similar study design).

\section{Statistical and GIS analyses}

We used four logistic regressions with a backward stepwise procedure to analyse factors affecting nestsite selection at various spatial scales. Data on nest-site features were used to discriminate between:

(1) the characteristics of 25 cliff nests and 25 random cliffs (selection at the cliff-level: Appendix 1)

(2) the woodland characteristics in the immediate neighbourhood of 25 tree nests and of 25 random trees (selection at the nest-stand level: Appendix 1)

(3) the features of each of the above 25 nesting trees and those of one tree which was (i) randomly chosen from among those measured within the 0.04-ha plot around each nest and (ii) judged capable of supporting a hypothetical buzzard nest at $>8 \mathrm{~m}$ high, which allowed us to assess whether buzzards selected specific features of the nesting tree from among those available in its immediate vicinity (selection at the nest-tree level)

(4) the landscape features of 40 nest-sites and 40 random sites (selection at the landscape-level: Appendix 1)

To reduce collinearity and the number of variables presented to the multivariate models, we employed the method of variable reduction proposed by Green (1979) and commonly employed in habitat selection studies (e.g. Austin et al., 1996; Sergio \& Bogliani, 2000 and references therein). In this method, pairs of strongly intercorrelated, explanatory variables $(r>0.6)$ are considered to be estimates of one underlying factor. Only one out of the two is retained for analysis, usually the one most likely to be perceived as more important by the study organism. Of the remaining variables, only those for which significant univariate differences $(P<0.1)$ were detected between nests and random locations were included in multivariate analyses.

For the analysis at the landscape scale, the predictive value of the logistic model was validated by applying it to 20 random locations and 20 nests (each from a different territory) located in the Noce study area (i.e. the farthest from the Lugano plot).

\section{Factors affecting breeding performance}

We used multiple regression to test the effect of environmental features on the number of young fledged within 31 territories checked at least once for breeding performance. To ensure data independence, for each territory we used data on breeding performance from one randomly selected year in which the territory was checked. To reduce the number of variables presented to the model, we employed only those that entered the above logistic models and those that were significantly related to the dependent variable in univariate correlations.

\section{Population-level effects}

For each of the 10 study areas, we measured landscape structure and composition (e.g. extent of land-uses, Shannon index of habitat diversity, length of habitat edges/unit area) by accessing various GIS land-use maps (C.E.C., 1993; Regione Lombardia, Direzione Generale della Presidenza, Servizio Sistema Informativo, 1998; Servizio Foreste, 1999). We then correlated average buzzard density with such environmental variables.

In all analyses, logistic and multiple regression models were run through a standard and a generalised linear model procedure (GLM, software GLIM 4). We then retained the model with the highest predictive power. GLM modelling procedures follow Crawley (1993). For all analyses, means are given \pm 1 standard error (SE), tests are two-tailed and statistical significance was set at $\alpha \leq 0.05$. When multiple tests were performed on the same data set, the sequential Bonferroni correction was used to adjust the significance level (Rice, 1989).

\section{RESULTS}

\section{Selection of cliff-sites}

After variable reduction (see Methods and Table 1), three variables were presented to the stepwise logistic regression: cliff height, height of cliff complex and width of cliff complex. Of these, only cliff height ( $\log _{e}$ transformed) had access to the logistic model ( $B=$ $1.48 \pm 0.68$, Wald $=4.73, P=0.03$ ), which correctly 
Table 1. Environmental variables recorded at 25 common buzzard cliff nests and at 25 cliffs randomly chosen in the study area (Italian pre-Alps, 1993-2002)

\begin{tabular}{lcc}
\hline Variable & $\begin{array}{l}\text { Cliff nests } \\
(n=25)\end{array}$ & $\begin{array}{l}\text { Random cliffs } \\
(n=25)\end{array}$ \\
\hline Nest height $^{\mathrm{a}}$ & $28.1 \pm 3.9$ & \\
& & \\
Height of cliff complex $^{\mathrm{b},+}$ & $69.2 \pm 8.9$ & $50.0 \pm 7.1$ \\
Width of cliff complex $^{\mathrm{b},+}$ & $233.6 \pm 38.5$ & $138.8 \pm 27.3$ \\
Elevation & $606.8 \pm 27.9$ & $572.4 \pm 32.6$ \\
\% slope ${ }^{\mathrm{b}, * *}$ & $17.2 \pm 0.8$ & $14.3 \pm 0.6$ \\
Micro-ruggedness index $^{\mathrm{c}, * *}$ & $25.5 \pm 1.4$ & $20.7 \pm 0.9$ \\
Distance to open $^{\mathrm{c}}$ & $144.0 \pm 39.6$ & $173.6 \pm 29.8$ \\
Distance to path $^{\mathrm{c}}$ & $202.9 \pm 25.3$ & $162.1 \pm 21.1$ \\
Distance to road $^{\mathrm{c}}$ & $454.9 \pm 54.0$ & $412.5 \pm 54.7$ \\
\hline
\end{tabular}

Only significant variables (in univariate comparisons between

nesting trees) are shown for conciseness of presentation; full table available on request from F.S.

Univariate differences between the two samples were tested by means of $t$-tests.

${ }^{+} 0.05<P<0.1 ;{ }^{*} P<0.05 ;{ }^{*} P<0.01$.

${ }^{a}$ Only measured for nesting cliffs.

${ }^{\mathrm{b}} t$-test carried out on the variable $\log _{\mathrm{e}}$ transformed.

${ }^{c} t$-test carried out on the variable square root transformed.

reclassified $60 \%$ of the nests and $72 \%$ of the random cliffs (overall reclassification $=66 \%$ ). Cliff height was positively correlated with nest height $(r=0.55, n=25$, $P=0.008)$.

\section{Selection of forest-sites: nest-stand level}

Of the 25 measured nests, 24\% were on sweet chestnut, $12 \%$ on oak species, $12 \%$ on Scots pine (Pinus sylvestris), $8 \%$ on beech and the remaining $44 \%$ on other seven tree species. It was impossible to compare such a pattern with the one from random trees by $X^{2}$ analysis because of the high incidence of expected frequencies that were less than 5. When trees were classified as sweet chestnut or not, buzzards were not selective with respect to tree species $\left(X^{2}=2.17, P=0.14\right)$. Of the seven variables tested for model entrance (Table 2), only the percentage of trees covered by ivy (arcsine square-root transformed) entered the stepwise logistic GLM (with binomial errors and a logit link function: Crawley, 1993; $B=210.4 \pm 134.3$, $X^{2}=0.07, P=0.002 ; B$ for constant $=-0.7 \pm 0.4$ ), which correctly reclassified $76 \%$ of the buzzard nests and $88 \%$ of the random trees (overall $=82 \%$ ). The percentage of trees covered by ivy was positively related to mean tree height in the stand ( $r=0.30, n=50, P=0.03)$.

\section{Selection of forest-sites: nest-tree level}

Univariate, paired comparisons between each nest tree and one random tree in its immediate surroundings (0.04 ha plot) showed that buzzards selected taller trees with a larger diameter at breast height (Table 3). The latter
Table 2. Environmental variables measured at 25 common buzzard tree nests and at 25 trees randomly chosen in the study area (Italian pre-Alps, 1993-2002)

\begin{tabular}{lcc}
\hline Variable & $\begin{array}{l}\text { Nest trees } \\
(n=25)\end{array}$ & $\begin{array}{l}\text { Random trees } \\
(n=25)\end{array}$ \\
\hline Nest height & $14.2 \pm 0.9$ & $12.9 \pm 0.6$ \\
& $36.0^{\mathrm{a}}$ & $0.0^{\mathrm{a}}$ \\
Covered by ivy & $\mathrm{c}, * *$ & $12.2 \pm 0.4$ \\
Mean tree height** $^{*}$ \% with ivy,,$* * *^{\mathrm{b}}$ & $14.5 \pm 0.6$ & $0.7 \pm 0.4$ \\
Tree species richness $^{+}$ & $12.3 \pm 2.6$ & $4.3 \pm 0.3$ \\
Micro-ruggedness index $^{\mathrm{a}, * * *}$ & $3.6 \pm 0.3$ & $11.9 \pm 0.8$ \\
Elevation $^{*}$ & $15.6 \pm 1.4$ & $599.0 \pm 40.4$ \\
Distance to open $^{\mathrm{c}}$ & $491.8 \pm 32.6$ & $57.2 \pm 9.1$ \\
Distance to path $^{\mathrm{d}}$ & $57.3 \pm 9.2$ & $107.0 \pm 21.4$ \\
Distance to road $^{\mathrm{d}}$ & $163.9 \pm 30.0$ & $291.1 \pm 65.2$ \\
Distance to village $^{\mathrm{d},+}$ & $258.0 \pm 38.4$ & $600.0 \pm 114.9$ \\
\end{tabular}

Variables related to woodland structure were collected within a 0.04 circular plot centred on the nest or random site. Only significant variables (in univariate comparisons between nesting trees and random trees and between nesting trees and nesting cliffs) are shown for conciseness of presentation; full table available on request from F.S. Univariate differences between the two samples were tested by means of $t$-tests.

${ }^{+} 0.05<P<0.1$; ${ }^{*} P<0.05 ;{ }^{* *} P<0.01 ;{ }^{* * *} P<0.001$.

${ }^{a}$ Percentage of nesting or random trees covered by ivy. Difference tested by means of a $X^{2}$ test on the count data.

${ }^{\mathrm{b}} t$-test carried out on the variable transformed in the arcsine square root of the proportion.

${ }^{c} t$-test carried out on the variable square root transformed.

${ }^{\mathrm{d}} t$-test carried out on the variable $\log _{\mathrm{e}}$ transformed.

Table 3. Environmental variables measured at 25 common buzzard tree nests and at 25 trees, each one randomly chosen within a 0.04 circular plot centred on each nest tree (Italian pre-Alps, 1993-2002)

\begin{tabular}{lcc}
\hline Variable & $\begin{array}{l}\text { Nests trees } \\
(n=25)\end{array}$ & $\begin{array}{l}\text { Random trees } \\
(n=25)\end{array}$ \\
\hline Dbh $^{* * *}$ & $45.4 \pm 2.7$ & $20.1 \pm 1.4$ \\
Tree height $^{\mathrm{a} *}$ & $19.2 \pm 0.8$ & $15.6 \pm 0.6$ \\
Branch height $^{\mathrm{a}}$ & $7.3 \pm 1.0$ & $5.6 \pm 0.7$ \\
Covered bv ivv $^{\mathrm{b} * *}$ & 36.0 & 0.0 \\
\hline
\end{tabular}

Univariate differences were tested by means of paired $t$-test.

${ }^{*} P<0.05 ;{ }^{* *} P<0.01 ;{ }^{* *} P<0.001$.

${ }^{\mathrm{a}} t$-test carried out on the variable $\log _{\mathrm{e}}$ transformed.

${ }^{b}$ Percentage of trees covered by ivy. Difference tested by means of a $X^{2}$ test on the count data.

variable was the only one to enter the logistic regression model, which correctly classified $88 \%$ of the nests and $92 \%$ of the random trees (overall $=90 \%: B=0.31 \pm 0.11$, Wald $=8.20, P=0.012$; $B$ for constant $=-8.29 \pm 2.84$ ).

\section{Comparison between cliff and tree nests}

To gain further insight into the process affecting the selection of a tree or a cliff nest, we compared the environmental features that could be collected for both 
Table 4. Environmental variables measured at the landscape scale at 40 common buzzard nest-sites and at 40 random sites (Italian pre-Alps, 1993-2002)

\begin{tabular}{lcc}
\hline Variable & $\begin{array}{l}\text { Buzzard nests } \\
(n=40)\end{array}$ & $\begin{array}{l}\text { Random locations } \\
(n=40)\end{array}$ \\
\hline \% slope $^{\mathrm{a}, * *}$ & $13.3 \pm 0.8$ & $10.5 \pm 0.5$ \\
Micro-ruggedness index $^{\mathrm{a}, * *}$ & $20.7 \pm 1.2$ & $15.8 \pm 0.8$ \\
Macro-ruggedness index $^{\mathrm{a}, * * *}$ & $68.0 \pm 3.1$ & $51.2 \pm 2.1$ \\
NND $^{\mathrm{a},+}$ & $1384.0 \pm 106.9$ & $1153.5 \pm 98.2$ \\
Distance to open $^{\mathrm{b}, * *}$ & $151.8 \pm 29.0$ & $300.9 \pm 32.2$ \\
Distance to building $^{\mathrm{a}, *}$ & $510.0 \pm 46.0$ & $394.4 \pm 40.5$ \\
Distance to village $^{\mathrm{a}, *}$ & $770.8 \pm 79.1$ & $583.2 \pm 74.2$ \\
\% urban $^{\mathrm{c},+}$ & $4.1 \pm 0.8$ & $8.8 \pm 1.9$ \\
Interspersion index $^{\mathrm{b}, * * *}$ & $15.2 \pm 0.7$ & $10.9 \pm 0.7$ \\
Woodland-open interspersion $^{\text {index }}{ }^{* *}$ & $5.0 \pm 0.6$ & $2.9 \pm 0.4$ \\
\hline
\end{tabular}

Only significant variables are shown for conciseness of presentation; full table available on request from F.S. Univariate differences between the two samples were tested by means of $t$-tests.

${ }^{+} 0.05<P<0.1$; ${ }^{*} P<0.05 ;{ }^{*} P<0.01$; ${ }^{* * *} P<0.001$.

${ }^{\mathrm{a}} t$-test carried out on the variable $\log _{\mathrm{e}}$ transformed.

${ }^{\mathrm{b}} t$-test carried out on the variable square root transformed.

${ }^{c} t$-test carried out on the variable transformed in the arcsine square root of the proportion.

nest types (Tables 1 and 2). Compared to tree nests, cliff nests were nearer to open areas and had higher values of nest height, micro-ruggedness index, elevation and distance to path and to road (all $t \geq 2.02, P<0.05$ ). Three of these variables entered a stepwise logistic regression: height of the nest above ground ( $\log _{\mathrm{e}}$ transformed, $B=$ $2.49 \pm 1.15$, Wald $=4.64, P=0.031$ ), distance to open areas (square-root transformed, $B=-0.29 \pm 0.10$, Wald $=8.32, P=0.016$ ) and distance to road (square-root transformed, $B=0.36 \pm 0.11$, Wald $=10.17, P=0.004$ ). The model correctly reclassified $80 \%$ of the cliff nests and $92 \%$ of the tree nests (overall $=86 \%$ ).

\section{Selection of nest-sites: landscape-level}

Of the 10 variables tested for model entrance (Table 4), four had access to the logistic model: interspersion index $(B=0.51 \pm 0.14$, Wald $=13.2, P=0.0004)$, macroruggedness index $\left(\log _{\mathrm{e}}\right.$ transformed, $B=4.26 \pm 1.70$, Wald $=6.3, P=0.048$ ), distance to building (loge transformed, $B=1.90 \pm 0.71$, Wald $=7.2, P=0.028$ ) and NND ( $\log _{\mathrm{e}}$ transformed, $B=2.30 \pm 0.83$, Wald $=$ $7.7, P=0.024)$. The model correctly reclassified $82.5 \%$ of the nests and $85.0 \%$ of the random sites (overall = 83.8\%). When validated on the independent data from the Noce area, the model correctly classified $80 \%$ out of 20 nests and $75 \%$ out of 20 random locations.

\section{Factors affecting breeding performance}

Two variables entered a stepwise multiple regression with the number of fledged young per territorial pair as the dependent variable: \% heath $(B=1.80 \pm 0.53, t=3.4$,

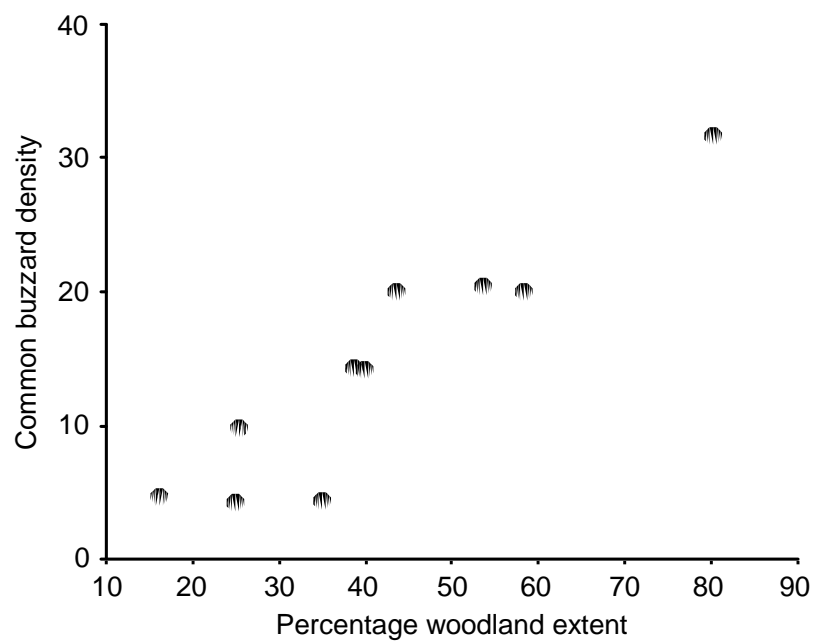

Fig. 2. Population density of common buzzards in relation to percentage extent of woodland in 10 study areas in the Italian preAlps (1996-2002).

$P=0.012)$ and $\%$ farmland $(B=-7.17 \pm 2.52, t=-2.8$, $P=0.016 ; R^{2}=0.36$ ). Two variables entered a stepwise multiple regression with the number of young fledged per successful pair as the dependent variable: \% heath $(B=$ $0.59 \pm 0.28, t=2.1, P=0.048$ ) and \% rocky outcrops $\left(B=2.17 \pm 0.61, t=3.5, P=0.004 ; R^{2}=0.50\right)$.

\section{Population-level effects}

Buzzard density was positively related to the percentage extent of woodland ( $r_{s}=0.91, P=0.001$ : Fig. 2 ) and negatively related to the density of eagle owls in each area $\left(r_{s}=-0.72, P=0.040\right)$.

\section{DISCUSSION}

Buzzards were selective at all spatial scales analysed. At the micro-scale, the birds selected features of cliffs and trees that allowed them to position nests high above ground in a concealed location. In particular, many treenests were on very mature trees (see also Cerasoli \& Penteriani, 1996) fully covered by ivy, so that the nest itself was completely surrounded by ivy and often impossible to see from the ground. Building concealed nests high above ground has been previously reported (Jêdrzejewski, Jêdrzejewska \& Keller, 1988; Hubert, 1993) and is likely to minimise potential predation by human beings and other terrestrial predators. In our area, mammalian nestpredation is scarce, but nest robbing by humans was frequent up until recently (Sergio et al., 2002, 2003d). The active avoidance of potential human predation was further suggested by the landscape-level avoidance of roads and may also explain the high frequency of cliff nests (Sergio et al., 2002), which are usually more difficult to access, higher above ground and farther from roads than tree nests. Similar results have been obtained for the sympatric black kite (Milvus migrans), suggesting that 
both species responded to a similar predation pressure, despite selecting different foraging habitats (Sergio et al., 2003d).

At the landscape-level, buzzards selected rugged areas with a high availability of habitat boundaries and were far from conspecifics. These features were probably related to food availability. Buzzards are opportunistic predators with a varied diet, locally dominated by a few main prey species (Tubbs, 1974). Higher availability of habitat boundaries implies higher habitat heterogeneity, which may allow rapid prey-switching when the availability of any of the main prey declines (Steenhof \& Kochert, 1988). Similar results were obtained by Austin et al. (1996) in the Scottish uplands. A rugged topography may, in addition, increase habitat heterogeneity, while simultaneously maximising the area effectively available for hunting within a certain radius of the nest (see Penteriani \& Faivre, 1997 and McLeod et al., 2002 for similar results). Finally, avoidance of conspecifics is to be expected in a solitary nesting raptor with a uniform dispersion of nest-sites (e.g. Sergio, Marchesi \& Pedrini, 2004). Such spacing behaviour may allow population density to be fine-tuned on resource availability, while simultaneously minimising intraspecific competition (e.g. Newton, 1979; Village, 1983).

Buzzard productivity was (1) positively related to the availability of arid habitats (rocky outcrops and dry heath), which are rich in snakes (Sergio, 2002), the local main prey and (2) negatively related to farmland availability, which is poor in prey species (Sergio et al., 2003b). Finally, buzzard density was negatively related to eagle owl abundance and positively related to woodland availability. Eagle owl predation on buzzard adults and nestlings has been frequently reported (Olsson, 1979; Penteriani, 1996; Marchesi et al., 2002). We have previously shown that this powerful and aggressive owl may limit the populations of mediumsized raptors (Sergio et al., 2003a; Sergio, Pedrini \& Marchesi, 2003c). The positive relationship between woodland availability and buzzard density may also be integral to a strategy of owl avoidance by buzzards through habitat segregation (e.g. Polis \& Holt, 1992; Newton, 1998). In fact, eagle owl density usually peaks in very open landscapes and declines with the availability of woodland, which is usually an unsuitable hunting habitat for this large-bodied species (e.g. Sergio et al., 2004; Penteriani et al., 2001b; Penteriani, Gallardo \& Roche, 2002). However, it should also be noted that woodland is considered the ancestral habitat of common buzzards (Jêdrzejewski et al., 1988). Some populations can breed successfully at high densities in very forested regions (Tubbs, 1974; Newton, Davis \& Davis, 1982; Gibbons et al., 1994) and, in our Lugano study area, almost $70 \%$ of 1192 identified food items were of woodland origin. Therefore, the additive effects of low predation risk and other woodland-related advantages, such as higher food or nest-site availability, may have caused the positive effect of woodland on density. In conclusion, buzzard settlement, density and productivity were affected by the complex interplay of food availability, human persecution and predation risk, all of them probably mediated by the availability of safe nest-sites affording ready access to a diverse food supply.

\section{Implications: conservation guidelines}

The current conversion of coppice woodland to mature forests is likely to benefit buzzard populations by increasing nest-site availability. Mature forests are also likely to support higher densities of their main prey species than coppice woodland (e.g. small mammals: Gurnell, Hicks \& Whitbread, 1992), especially because most of the current coppice is composed of sweet chestnut, which is characterised by an extreme lack of ground flora in the herbaceous and bush layers, leading to a poor faunal assemblage (Fuller, 1992; Gurnell et al., 1992; I.P.L.A., 2000). In contrast, land abandonment and the consequent loss of open habitats may disfavour buzzards by decreasing habitat heterogeneity and the availability of dry heath. This habitat is extremely rare in the Alps and typically occurs in areas with igneous rocks, acidic soils and frequent (artificial) burning. Its rarity and rich herpetofauna (unpublished data) makes it an important component of regional biodiversity and it should be actively preserved.

Based on our results, we propose the following guidelines:

(1) The conversion of neglected coppice to mature forest is favoured, but it should be managed through sylvicultural systems to allow the continual availability of mature trees (e.g. Penteriani \& Faivre, 2001; Seymour \& Hunter, 1999).

(2) Some scattered trees or clumps of trees should be left to grow indefinitely, especially near cliffs, and some woodland patches should be left to be covered by ivy since this is also favoured by other raptors (e.g. Sergio et al., 2003d) and increases the structural and invertebrate diversity, with minor or no timber loss (Andrews \& Rebane, 1994; Broad, 1999).

(3) Ideally, some patches of actively-managed short rotation coppice mainly composed of oak species should be left, so as to increase horizontal and vertical heterogeneity (the early stages of coppiced oak woodland can support high numbers of vertebrate and invertebrate species, e.g. Fuller, 1992; GreatorexDavies \& Marrs, 1992; Gurnell et al., 1992; Fuller \& Warren, 1993).

(4) All patches of dry heath should be preserved and subsidies enhanced for their active management through prescribed, controlled burning at least once every 10-20 years (e.g. see prescriptions in Dolmand \& Land, 1995).

Such guidelines would simultaneously:

a. favour buzzards and other raptor species (based on previous results, e.g. Pedrini \& Sergio, 2002; Sergio et al., 2003b,d, 2004)

b. satisfy the needs of the local agro-forestry industry (e.g. by favouring the conversion of neglected coppice to more economically profitable mature forest) 
(c) probably benefit broader-scale biodiversity (based on current knowledge, e.g. Sergio, 2002; Sergio \& Pedrini, 2004).

\section{Acknowledgements}

We thank G. E. Austin, M. Licantropi, J. D. Reynolds and an anonymous referee for comments on a previous draft of the manuscript and A. Boto and A. Scandolara for help in the field. Part of this research was funded by the Autonomous Province of Trento (Project 'Biodiversità').

\section{REFERENCES}

Andrews, J. \& Rebane, M. (1994). Farming and wildlife. A practical management handbook. Sandy: RSPB.

Austin, G. E., Thomas, C. J., Houston, D. C. \& Thompson, B. A. (1996). Predicting the spatial distribution of buzzard Buteo buteo nesting areas using a Geographical Information System and remote sensing. J. Appl. Ecol. 33: 1541-1550.

Bennet, E. L. (2000). Timber certification: where is the voice of the biologist? Conserv. Biol. 14: 921-923.

Broad, K. (1999). Caring for small woods. London: Earthscan.

Buckley, G. P. (Ed.) (1992). Ecology and management of coppice woodlands. London: Chapman and Hall.

C.E.C. (Commission of the European Communities) (1993). CORINE Land Cover - Guide technique. Brussels: Office for Official Publications of the European Communities.

Cerasoli, M. \& Penteriani, V. (1996). Nest-site and aerial meeting point selection by common buzzards (Buteo buteo) in Central Italy. J. Raptor Res. 30: 130-135.

CIPRA (2001). Rapporto sullo stato delle Alpi 2: dati, fatti, problemi, proposte. Torino: CDA.

Crawley, M. J. (1993). GLIM for ecologists. Oxford: Blackwell Science.

Dolmand, P. M. \& Land, R. (1995). Lowland heathland. In Managing habitats for conservation: 267-291. Sutherland, W. J. \& Hill, D. A. (Eds). Cambridge: Cambridge University Press.

Fuller, R. J. (1992). Effects of coppice management on woodland breeding birds. In Managing habitats for conservation: 167-210. Sutherland, W. J. \& Hill, D. A. (Eds). Cambridge: Cambridge University Press.

Fuller, R. J. \& Warren, M. S. (1993). Coppice woodlands: their management for wildlife. Peterborough: Joint Nature Conservation Committee.

Gibbons, D., Gates, S., Green, R. E., Fuller, R. J. \& Fuller, R. M. (1994). Buzzards Buteo buteo and Ravens Corvus corax in the uplands of Britain: limits to distribution and abundance. Ibis 137(Suppl.): S75S84.

Greatorex-Davies, J. N. \& Marrs, R. H. (1992). The quality of coppice woods as habitats for invertebrates. In Managing habitats for conservation: 271-296. Sutherland, W. J. \& Hill, D. A. (Eds). Cambridge: Cambridge University Press.

Green, R. H. (1979). Sampling design and statistical methods for environmental biologists. New York: John Wiley \& Sons.

Gurnell, J., Hicks, M. \& Whitbread, S. (1992). The effects of coppice management on small mammal populations. In Ecology and management of coppice woodlands: 213-232. Buckley, G. P. (Ed.). London: Chapman and Hall.

Hooge, P. N. \& Eichenlaub, B. (1997). Movement. Animal movement extension to ArcView ver. 1.1. Anchorage: Alaska Biological Science Center, U.S. Geological Survey.

Hubert, C. (1993). Nest-site habitat selected by Common Buzzard (Buteo buteo) in southwestern France. J. Raptor Res. 27: 102-105.

I.P.L.A. (2000). Sweet chestnut coppice. Cuneo: Blu Edizioni.
J£drzejewski, W., J£drzejewska, B. \& Keller, M. (1988). Nest site selection by the Buzzard Buteo buteo L. in the extensive forests of eastern Poland. Biol. Conserv. 43: 145-158.

Lichtenbergen, E. (1994). Die Alpen in Europa. Osterreichische Akademie der Wissenschften, Veröff. Komm. Humanökologie 5: 5386.

Marchesi, L., Sergio, F. \& Pedrini, P. (2002). Costs and benefits of breeding in human-altered landscapes for the Eagle owl Bubo bubo. Ibis 144: 164-177.

Matthews, J. D. (1989). Silvicultural systems. Oxford: Oxford University Press.

McLeod, D. R. A., Whitfield, D. P., Fielding, A. H., Hawarth, P. F. \& McGrady, M. J. (2002). Predicting home range use by golden eagles Aquila chrysaetos in western Scotland. Avian Sci. 4: 183198.

Newton, I. (1979). Population ecology of raptors. Berkhamsted: T \& A D Poyser.

Newton, I. (1998). Population limitation in birds. London: Academic Press.

Newton, I., Davis, P. E. \& Davis, J. E. (1982). Ravens and buzzards in relation to sheep-farming and forestry in Wales. J. Appl. Ecol. 19: 681-706.

Olsson, V. (1979). Studies on a population of Eagle owls, Bubo bubo (L.), in southeast Sweden. Viltrevy 11: 3-99.

Pain, D. J. \& Pienkowski, M. W. (Eds) (1997). Farming and birds in Europe: the Common Agricultural Policy and its implications for bird conservation. London: Academic Press.

Pedrini, P. \& Sergio, F. (2001). Golden eagle Aquila chrysaetos density and productivity in relation to land abandonment and forest expansion in the Alps. Bird Study 48: 194-199.

Pedrini, P. \& Sergio, F. (2002). Regional conservation priorities for a large predator: golden eagles (Aquila chrysaetos) in the Alpine range. Biol. Conserv. 103: 163-172.

Penteriani, V. (1996). The Eagle Owl. Bologna: Edagricole.

Penteriani, V. \& Faivre, B. (1997). Breeding density and landscapelevel habitat selection of common buzzards (Buteo buteo) in a mountain area (Abruzzo Apennines, Italy). J. Raptor Res. 31: 208212.

Penteriani, V. \& Faivre, B. (2001). Effects of harvesting timber stands on goshawk nesting in two European areas. Biol. Conserv. 101: 211216.

Penteriani, V., Faivre, B. \& Frochot, B. (2001a). An approach to identify factors and levels of nesting habitat selection: a cross-scale analysis of Goshawk preferences. Ornis Fennica 78: 159-167.

Penteriani, V., Gallardo, M., Roche, P. \& Cazassus, H. (2001b). Effects of landscape spatial structure and composition on the settlement of the eagle owl Bubo bubo in a Mediterranean habitat. Ardea 89: 331-340.

Penteriani, V., Gallardo, M. \& Roche, P. (2002). Landscape structure and food supply affect eagle owl (Bubo bubo) density and breeding performance: a case of intra-population heterogeneity. J. Zool. (Lond.) 257: 365-372.

Polis, G. A. \& Holt, R. D. (1992). Intraguild predation: the dynamics of complex trophic interactions. Trends Ecol. Evol. 7: 151-154.

Redpath, S., Madders, M., Donnelly, E., Anderson, B., Thirgood, S., Martin, A. \& McLeod, D. (1998). Nest site selection by hen harriers in Scotland. Bird Study 45: 51-61.

Regione Lombardia, Direzione Generale della Presidenza, Servizio Sistema Informativo (1998). “La Cartografia.” Milano:Regione Lombardia.

Rice, W. R. (1989). Analyzing tables of statistical tests. Evolution 43: 223-225.

Scandolara, C. \& Sergio, F. (2001). Diet of common buzzards Buteo buteo in the central-western pre-Alps. Avocetta 25: 247.

Sergio, F. (2002). Factors affecting richness of amphibian and reptile species in the Trento Region. In Atlas of amphibians and reptiles of the Trento Region (1987-1996, with updates to 2001): 99-103. Caldonazzi, M., Pedrini, P. \& Zanghellini, S. (Eds). Trento: Museo Tridentino di Scienze Naturali. 
Sergio, F. \& Bogliani, G. (2000). Hobby Falco subbuteo nest-site selection and productivity in relation to intensive agriculture and forestry. J. Wildl. Manage. 64: 637-646.

Sergio, F. \& Pedrini, P. (2004). Factors affecting richness of nesting and wintering bird species in the Trento Region. In Atlas of breeding and wintering birds of the Trento Region (1987-1996, with updates to 2001): in press. Caldonazzi, M., Pedrini, P. \& Zanghellini, S. (Eds). Trento: Museo Tridentino di Scienze Naturali.

Sergio, F., Boto, A., Scandolara, C. \& Bogliani, G. (2002). Density, nest-sites, diet, and productivity of common buzzards (Buteo buteo) in the Italian pre-Alps. J. Raptor Res. 36: 24-32.

Sergio, F., Marchesi, L. \& Pedrini, P. (2003a). Spatial refugia and the coexistence of a diurnal raptor with its intraguild owl predator. $J$. Anim. Ecol. 72: 232-245.

Sergio, F., Pedrini, P. \& Marchesi, L. (2003b). Reconciling the dichotomy between single species and ecosystem conservation: black kites (Milvus migrans) and eutrophication in pre-Alpine lakes. Biol. Conserv. 110: 101-111.

Sergio, F., Pedrini, P. \& Marchesi, L. (2003c). Spatio-temporal shifts in gradients of habitat quality for an opportunist avian predator. Ecography 26: 243-255.

Sergio, F., Pedrini, P. \& Marchesi, L. (2003d). Adaptive selection of foraging and nesting habitat by black kites (Milvus migrans) and its implications for conservation: a multi-scale approach. Biol. Conserv. 112: 351-362.

Sergio, F., Marchesi, L. \& Pedrini, P. (2004). Integrating individual habitat choices and regional distribution of a biodiversity indicator and top predator. J. Biogeog. 31: 619-628.

Servizio Foreste (1999). Carta fisionomica della copertura forestale in Trentino. Trento: Provincia Autonoma di Trento.

Seymour, R. S. \& Hunter, M. L. Jr (1999). Principles of ecological forestry. In Maintaining biodiversity in forest ecosystems: 22-61. Hunter, M. L. Jr (Ed.). Cambridge: Cambridge University Press.

Shannon, C. E. \& Wiener, W. (1949). The mathematical theory of communication. Urbana: University of Illinois Press.

Steenhof, K. \& Kochert, M. N. (1988). Dietary responses of three raptor species to changing prey densities in a natural environment. J. Anim. Ecol. 57: 37-48.

Tosi, G., Zilio, A., Baratelli, D., Chiarenti, B., Piccinini, S., Preatoni, D. G., Scherini, G. \& Viganò, A. (2000). Conoscenza delle Risorse Ambientali della provincia di Varese: Progetto SIT-FAUNA. Varese: Università degli Studi dell'Insubria and Provincia di Varese.

Tubbs, C. R. (1974). The buzzard. Newton Abbot: Davis \& Charles.

Village, A. (1983). The role of nest-site availability and territorial behaviour in limiting the breeding density of kestrels. J. Anim. Ecol. 52: 635-645.

APPENDIX 1. Environmental variables measured at common buzzard nests and random sites (central Italian pre-Alps, 1993-2002)

\begin{tabular}{|c|c|}
\hline Variable & Description \\
\hline Cliff level $^{\mathrm{a}}$ & Characteristics of the nesting cliff and its immediate surroundings \\
\hline Nest height (m) & Height of the nest above the ground \\
\hline Cliff height (m) & Height of the cliff \\
\hline Cliff width (m) & Width of the cliff in the widest portion \\
\hline Height of cliff complex (m) & Maximum height of the cliff complex \\
\hline Width of cliff complex (m) & Maximum width of the cliff complex \\
\hline$\%$ vegetation cover & $\%$ of the cliff face covered by vegetation \\
\hline Cliff climbing & Cliff regularly used by cliff-climbers (0) or not (1) \\
\hline Nest-stand level ${ }^{\mathrm{a}}$ & Characteristics of the nest tree and the woodland in its surroundings \\
\hline Dbh $(\mathrm{cm})$ & Diameter at breast height of the nest tree \\
\hline Nest height (m) & Height of the nest above the ground \\
\hline Branch height (m) & Height of the lowest live branches of the nest tree \\
\hline Tree height (m) & Height of the nest tree \\
\hline Covered by ivy & Nest tree covered by ivy (1) or not $(0)$ \\
\hline Mean dbh $(\mathrm{cm})^{\mathrm{b}}$ & Mean diameter at breast height in the 0.04 ha plot \\
\hline Mean tree height $(\mathrm{m})^{\mathrm{b}}$ & Mean tree height in the 0.04 ha plot \\
\hline Mean branch height (m) & Mean height of the lowest live branches for trees in the 0.04 ha plot \\
\hline Tree density & Number of trees/ha in the 0.04 ha plot \\
\hline$\%$ basal area ${ }^{\mathrm{b}}$ & Total tree basal area expressed as percentage of 0.04 ha \\
\hline \% canopy cover & $\%$ of the 0.04 plot under the cover of the canopy \\
\hline$\%$ shrub cover & $\%$ of the ground in the 0.04 ha plot covered by shrubs \\
\hline$\%$ live trees & $\%$ of the trees in the 0.04 ha plot which are alive \\
\hline \% with ivy & $\%$ of trees in the 0.04 ha plot covered by ivy \\
\hline Tree species richness & Richness of tree species in the 0.04 ha plot \\
\hline Tree species diversity & Shannon index of diversity of tree species in the 0.04 ha plot \\
\hline$\%$ rocky ground cover & $\%$ of the ground in the 0.04 ha plot composed of rocky outcrops \\
\hline Landscape-level & Landscape structure and composition within $700 \mathrm{~m}$ of the nest \\
\hline Elevation (m) & Elevation above sea level (a.s.l.) \\
\hline$\%$ slope & $\%$ slope within $100 \mathrm{~m}$ of the nest \\
\hline Micro-ruggedness index & Number of contour lines crossed by two N-S and W-E transects of $200 \mathrm{~m}$ \\
\hline Macro-ruggedness index & Number of contour lines crossed by two N-S and W-E transects of $1.4 \mathrm{~km}$ \\
\hline $\mathrm{NND}(\mathrm{m})$ & Nearest neighbour distance \\
\hline Distance to open (m) & Distance to the nearest open habitat \\
\hline Distance to cliff (m) & Distance to the nearest cliff \\
\hline Distance to path (m) & Distance to the nearest path \\
\hline
\end{tabular}


APPENDIX 1. Continued

\begin{tabular}{|c|c|}
\hline Variable & Description \\
\hline Distance to road (m) & Distance to the nearest asphalted road \\
\hline Distance to building (m) & Distance to the nearest inhabited building \\
\hline Distance to village (m) & Distance to the nearest village or town \\
\hline \% woodland ${ }^{\mathrm{c}}$ & \% extent of woodland within $700 \mathrm{~m}$ \\
\hline \% shrubs & $\%$ extent of shrub-dominated vegetation within $700 \mathrm{~m}$ \\
\hline \% heath & \% extent of dry heath (mainly dominated by Calluna vulgaris) within $700 \mathrm{~m}$ \\
\hline$\%$ rocky outcrops & $\%$ extent of rocky outcrops within $700 \mathrm{~m}$ \\
\hline$\%$ arid & $=\%$ shrubs $+\%$ heath $+\%$ rocky outcrops \\
\hline \% unmanaged grassland & $\%$ extent of unmanaged grassland within $700 \mathrm{~m}$ \\
\hline$\%$ managed grassland & $\%$ extent of cultivated grassland within $700 \mathrm{~m}$ \\
\hline$\%$ grassland & $=\%$ managed grassland $+\%$ unmanaged grassland \\
\hline$\%$ farmland & $\%$ extent of intensive farmland (does not include cultivated grassland) within $700 \mathrm{~m}$ \\
\hline$\%$ water & $\%$ extent of water bodies within $700 \mathrm{~m}$ \\
\hline$\%$ urban areas & $\%$ extent of urban areas within $700 \mathrm{~m}$ \\
\hline \% unmanaged open habitats & $=\%$ arid $+\%$ unmanaged grassland \\
\hline \% open habitats & $=\%$ arid $+\%$ grassland $+\%$ farmland \\
\hline Interspersion index & $\begin{array}{l}\text { Number of habitat edges crossed by two N-S and W-E transects of } 1.4 \mathrm{~km} \text { crossing each other } \\
\text { over the nest or at a random location }\end{array}$ \\
\hline Woodland-open interspersion index & $\begin{array}{l}\text { Number of edges between woodland and open habitats crossed by two N-S and W-E transects } \\
\text { of } 1.4 \mathrm{~km}\end{array}$ \\
\hline Woodland edge length (m) & $\begin{array}{l}\text { Length of the edge between woodland and open habitats within } 700 \mathrm{~m} \text { and expressed as } \\
\text { length } / \mathrm{km}^{2}\end{array}$ \\
\hline Habitat diversity & Shannon index of habitat diversity (Shannon \& Wiener, 1949) \\
\hline
\end{tabular}

${ }^{a}$ Elevation, \% slope, micro-ruggedness index and distance to path, road, building and village were also collected at the cliff and nest-stand level.

${ }^{\mathrm{b}}$ Also calculated separately for trees in the dbh interval class: $<20 \mathrm{~cm}, 20-40 \mathrm{~cm}$ and $>40 \mathrm{~cm}$.

${ }^{\mathrm{c}}$ Other woodland-variables recorded included the \% extent of forest dominated by sweet chestnut, oak, beech, European hop-hornbeam, conifers and their combinations (sweet chestnut + oak, oak + European hop-hornbeam, sweet chestnut + oak + European hop-hornbeam). 